\title{
Factors affecting the age at onset of puberty, ovulation rate and time of ovulation in Chinese Meishan gilts
}

\author{
L. S. Faillace, C. Biggs and M. G. Hunter* \\ Department of Physiology and Environmental Science, Faculty of Agricultural and Food Sciences, \\ University of Nottingham, Sutton Bonington Campus, Leics LE12 5RD, UK
}

\begin{abstract}
Experiments were carried out to study: the effects of season on age at puberty, the influence of reproductive age on ovulation rate, and the time interval from the onset of oestrus to ovulation in Chinese Meishan gilts. Gilts approaching puberty either in the spring $(n=88)$ or in the autumn $(n=40)$ were housed indoors under natural daylight conditions and observed daily for oestrous behaviour. Gilts approaching puberty in the spring were younger $(P<0.001)$ and more likely to reach puberty by 100 days of age $(P<0.01)$ than were those approaching puberty in the autumn. Ovulation rate was estimated in gilts at second $(n=22)$, third $(n=24)$, fourth $(n=18)$, fifth to ninth $(n=9)$ and tenth to twenty-first $(n=17)$ oestrous cycle and in primiparous Meishan sows $(n=12)$ by counting the number of corpora lutea or corpora albicantia at laparoscopy, laparotomy or at ovarian recovery following slaughter. Ovulation rate increased $(P<0.001)$ with reproductive age and approached that of primiparous sows only when gilts had experienced $\geq 10$ oestrous cycles (19.2 versus 21.0). The time interval between the onset of oestrus and ovulation was studied in six naturally cyclic Meishan gilts and nine Meishan gilts administered hCG at the onset of oestrus. All gilts were observed six times a day for the commencement of oestrous behaviour and were subsequently examined by laparoscopy at $32 \mathrm{~h}$ following onset of oestrus and every $8 \mathrm{~h}$ until ovulation, which was at a maximum of $56 \mathrm{~h}$. Relative to the onset of oestrus, gilts administered hCG ovulated earlier than did the control group (44.2 versus $48.7 \mathrm{~h}, P<0.05$ ) and at an interval of $42.2 \mathrm{~h}$ relative to the administration of hCG.
\end{abstract}

\section{Introduction}

The Chinese Meishan pig was imported into the UK so that factors responsible for their extreme prolificacy ( $>14$ pigs per litter, Cheng, 1983) could be studied. Although the precise mechanisms responsible for the enhanced prolificacy of this breed are not yet known, recent investigations into the physiology and genetics of Meishan pigs have shown that they benefit from reduced early embryonic mortality at any given ovulation rate, leading to large litters (Haley and Lee, 1990; Wilmut et al., 1992). Relatively little is known, however, about the other general reproductive characteristics of the breed. For example, there is disagreement about whether Meishan gilts can attain the increased ovulatory potential reported for Meishan sows and, if so, at what reproductive or chronological age this occurs (Anderson et al., 1992; Christenson, 1992). It has been suggested that the interval from the onset of behavioural oestrus to ovulation is longer in Meishan gilts (Terqui et al., 1990) and sows (Wilmut et al., 1992) than in European breeds, but the factors responsible for this longer period have not been ascertained. Recent evidence suggests

*Correspondence and reprint requests.

Received 11 February 1993. that the long oestrus to ovulation interval in Meishan pigs is due to the LH surge occurring later relative to the onset of behavioural oestrus (compared to Large-White hybrid gilts) and that this accounts for the differences between the breeds (Hunter et al., 1993). Characterizing the time course of events during oestrus in Meishan pigs is crucial, since any study of the late stages of folliculogenesis, oocyte maturation, ovulation or early embryonic events depends on the ability to predict accurately the time of ovulation relative to the onset of oestrus, the LH surge or the administration of hCG. Lastly, early puberty is a trait associated with the Meishan breed (Bazer et al., 1988a; Jin et al., 1992; Hunter et al., 1993), but little is known about how factors such as photoperiod, nutrition, body size, social environment, pheromonal cues, stress and confinement (recognized to influence age at puberty in European breeds: Christenson and Ford, 1979) affect a sexually precocious breed.

The present study was carried out using Meishan gilts to examine (1) seasonal and body weight effects on age at puberty, (2) ovulation rate in gilts of various reproductive ages and in primiparous sows and (3) the time interval from the onset of behavioural oestrus to ovulation in naturally cyclic gilts and in gilts administered hCG at the onset of oestrus. 


\section{Materials and Methods}

\section{Puberty and duration of cycle}

Five groups of Meishan gilts were transported at 8-11 weeks of age to the University of Nottingham. Three groups, transported in February to April (spring-maturing; $n=88$ ), and two groups, transported in September and October (autumnmaturing; $n=40$ ), were obtained at 8-11 weeks of age between 1989 and 1992. All gilts were descendants of Meishan pigs imported into the UK in 1987. Upon arrival at the University of Nottingham, gilts were housed indoors under natural daylight conditions, fed a complete ration once a day, given free access to water and observed daily for oestrous behaviour using a boar of the same breed. Detection of oestrus was carried out by visual assessment and although criteria such as vulval reddening and swelling were used to indicate the approach of oestrus, the only criterion used for the positive identification of oestrous behaviour by a gilt was an immobilized stance in response to the presence of a boar (Varley et al., 1989). At the onset of first behavioural oestrus, gilts from two spring-maturing $(n=62)$ and two autumn-maturing groups $(n=40)$ were weighed. After puberty, oestrous cycles continued to be monitored in the same manner and the duration of the cycle was recorded. Age at onset of puberty and duration of cycle were also recorded in Large-White hybrid gilts (Landrace $\times$ (Landrace $\times$ Large White); $n=82$ ) obtained from the University of Nottingham swine herd at 5-6 months of age and housed under the same conditions. Since these gilts were transported to the research herd facility in small groups over an extended period, we did not assess any seasonal effects on age at puberty.

\section{Ovulation rate}

Meishan gilts of various reproductive ages (second to twenty-first oestrous cycle: second $n=22$, third $n=23$, fourth $n=18$, fifth to ninth $n=10$, tenth to twenty-first $n=17)$ and primiparous Meishan sows $(n=12)$ were used to determine the effect of reproductive and chronological age on ovulation rate. Ovulation rate was determined either by visual observation or dissection of the ovaries. Visual observation was via laparoscopy or laparotomy and these procedures were performed during the mid-luteal phase to facilitate determination of the number of corpora lutea. Alternatively, ovulation rate was determined following slaughter by dissecting the ovaries and counting the number of corpora lutea (mid-luteal phase or gestation) or corpora albicantia (recently regressed corpora lutea in the follicular phase) present on the ovaries.

\section{Interval from oestrus to ovulation}

Six Meishan gilts (control group) approaching their second oestrus were observed six times a day (02:00, 06:00, 10:00, $14: 00,18: 00,22: 00 \mathrm{~h}$ ) for the commencement of oestrous behaviour by introducing the gilts to a Meishan boar. Oestrous behaviour was defined as indicated above. Gilts were subsequently examined by laparoscopy at $32 \mathrm{~h}$ following the observed onset of oestrus and were examined every $8 \mathrm{~h}$ until the time of ovulation which was at a maximum of $56 \mathrm{~h}$. An additional nine gilts approaching their second oestrus were similarly observed for oestrous behaviour and ovulation but were administered hCG (hCG group, 500 iu hCG injected i.m.; Sigma Chemical Company, St Louis, MO) at the first observation of a lordosis response. The onset of oestrus for both groups was assumed to have occurred midway between the time at which oestrus was first observed and the previous observation at which the animal was not in oestrus $(4 \mathrm{~h}$ before the time at which oestrus was first observed). The onset of ovulation was assumed to have occurred midway between the time at which ovulation was initially observed and the previous laparoscopic examination at which ovulation was not observed ( $8 \mathrm{~h}$ before the time at which ovulation was first observed).

\section{Statistical analyses}

Data were analysed using the analysis of variance procedure of the GENSTAT statistical package (GENSTAT 5 committee, 1989). Age and weight at the onset of puberty data were analysed using a statistical model in which treatment was the season of maturation. The proportion of gilts in each season of maturation class reaching puberty by 100 days of age or $24 \mathrm{~kg}$ bodyweight was analysed by $\chi^{2}$ analysis. Age at puberty data from all Meishan gilts were combined so that age at the onset of puberty could also be analysed in a model that included breed as treatment (Meishan versus Large-White hybrid). Duration of cycle data were analysed in a model that included oestrous cycle number, breed and their interaction. Differences in the duration of the cycle due to oestrous cycle number were analysed using orthogonal contrasts (cycle 1 versus cycle 2 and 3 ; cycle 2 versus cycle 3 ). Ovulation rate data were analysed by including the rank of the oestrous cycle in the model. Oestrous cycles $2-4$ were included as separate classes but cycles 5-9 and 10-21 were combined so that adequate numbers of gilts would be in each class. Ovulation rate data from primiparous sows were also included in the analysis and orthogonal contrasts were used to detect differences between reproductive age classes (i.e. primiparous sows versus gilts experiencing 10-21 cycles; gilts experiencing $<5$ cycles versus gilts experiencing 5-9 cycles). The onset of oestrus to ovulation interval data were analysed including treatment (control group versus hCG group) in the model.

\section{Results}

\section{Puberty and duration of cycle}

The mean age at the initial behavioural oestrus was 112.7 days $(\mathrm{SD}=28.5)$ at which time gilts weighed a mean of $32.4 \mathrm{~kg}$ $(\mathrm{SD}=10.0)$. In contrast, Large-White hybrid gilts were 230.6 days of age $(\mathrm{SD}=27.0)$ at first oestrus, which was significantly older $(P<0.001)$ than were Meishan gilts. Spring-maturing Meishan gilts were significantly younger $(P<0.001$, Fig. 1$)$ and were more likely to reach puberty by 100 days of age than were autumn-maturing Meishan gilts $(52 \%$ and $15 \%$ respectively, $P<0.01)$. Mean bodyweight at puberty did not differ between the season of maturation groups $(P>0.37)$; however, 


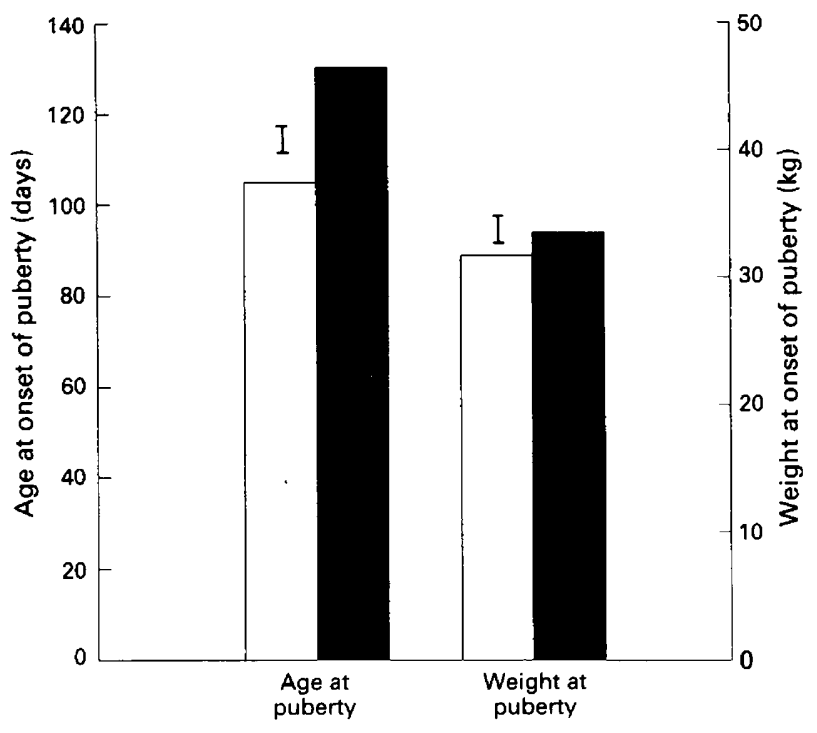

Fig. 1. Means and standard error of the deviance (SED) for age and weight at puberty for spring-maturing ( $\square ; n=88$ or 62 for age and weight at puberty, respectively) and autumn-maturing ( $\boldsymbol{\square} ; n=40$ for age and weight at puberty) Meishan gilts.

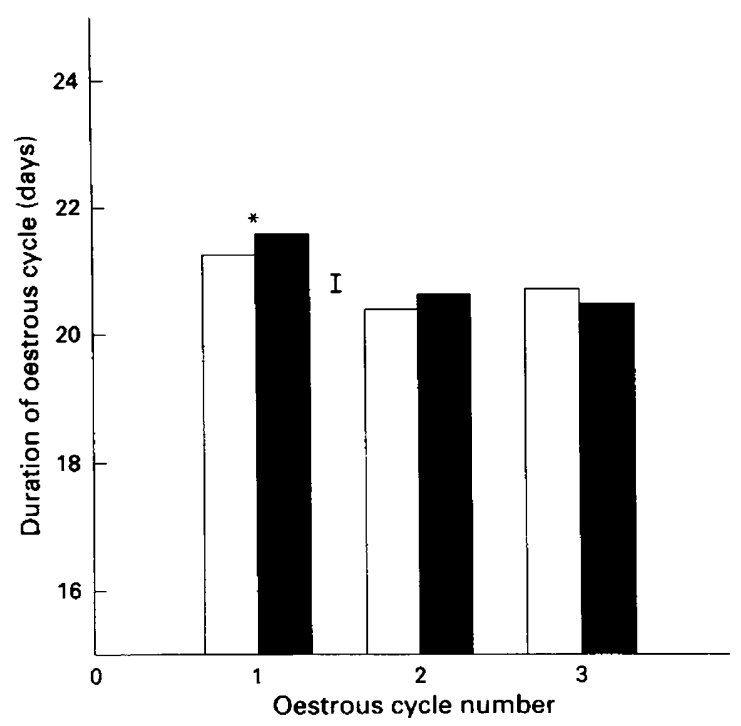

Fig. 2. Means and SED for duration of oestrous cycle (days) monitored over the initial three oestrous cycles in Large-White hybrid ( $\square$; $n=82)$ and Meishan $(\square ; n=128)$ gilts. ${ }^{*}$ Cycle 1 significantly longer than cycles 2 or $3(P<0.001)$.

the spring-maturing group had a higher percentage of gilts reaching puberty by $24 \mathrm{~kg}$ bodyweight than did the autumnmaturing group $(23 \%$ versus $5 \%, P<0.05)$.

Over the first three oestrous cycles, the mean time interval between day 0 of the oestrous cycle (initial day of standing oestrus) and the subsequent day 0 was 20.96 days (Fig. 2). This period did not differ from that recorded in Large-White hybrid gilts (20.81 days). Duration of the oestrous cycle was affected $(P<0.001)$ by cycle number overall and the duration of cycle 1

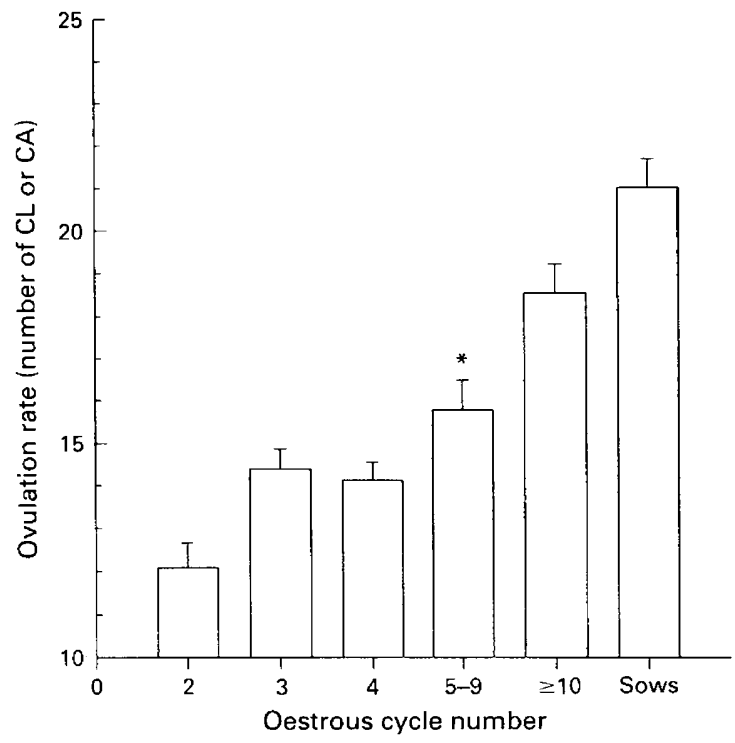

Fig. 3. Means and SEMs for ovulation rate (number of corpora lutea (CL) or corpora albicantia (CA)) in gilts at 2 nd $(n=22), 3 \mathrm{rd}(n=24)$, 4 th $(n=18), 5$ th to 9 th $(n=9)$ and 10th to 21 st $(n=17)$ oestrous cycle or in primiparous sows $(n=12) .{ }^{*}$ Ovulation rate at 5 th-9th oestrous cycles greater than that of gilts experiencing $\leq 4$ oestrous cycles $(P<0.001)$.

was longer $(P<0.001)$ than that of cycles 2 and 3. Cycles 2 and 3 were of similar duration $(P>0.10)$.

\section{Ovulation rate}

The estimation of ovulation rate by counting the number of corpora lutea or corpora albicantia indicated that the number of ova shed increased $(P<0.001)$ with reproductive age in Meishan gilts (Fig. 3). Gilts that had experienced $<5$ oestrous cycles had a lower ovulation rate $(P<0.01)$ than did gilts that had experienced 5-9 oestrous cycles. Gilts that had experienced an extended number of oestrous cycles $(\geq 10)$ had an ovulation rate which was numerically lower but not statistically different from that of primiparous sows (18.5 versus 21.0).

\section{Interval from oestrus to ovulation}

The control group of gilts ovulated at a mean time of $48.7 \mathrm{~h}$ after the onset of standing oestrus. Gilts administered hCG at the onset of oestrus ovulated earlier $(P<0.05)$ relative to the onset of oestrus (44.2 h, SED $=1.99$ ) which was at an interval of $42.2 \mathrm{~h}$ relative to the administration of hCG.

\section{Discussion}

The finding that Meishan pigs achieve puberty at an early age extends our previous findings (Hunter et al., 1993) and confirms previous reports from Meishan populations imported into France (Bazer et al., 1988a; Prunier and Chopineau, 1990) and the UK (Haley et al., 1990). Although the Meishan gilt only requires approximately half of the amount of time needed for European-type gilts to reach puberty (as was verified in the 
current study), it is likely that this precocious breed is subject to the same influences during the sexual maturation process as its European counterparts. The present investigation supports this notion as far as season of sexual maturation is concerned; gilts approaching puberty in a season of increasing daylength (spring-maturing) were younger at puberty than were gilts approaching puberty in a time of decreasing daylength (autumn-maturing). It has been reported that increasing photoperiod has a stimulatory effect on ovarian function in prepubertal Western gilts (Paterson and Pearce, 1990; Paterson et al., 1991) and although the involvement of the pineal gland in this phenomenon has been supported by Paterson et al. (1992), the mechanism by which increasing photoperiod stimulates earlier puberty is largely unknown. Since age at puberty was significantly lower in spring-maturing gilts while mean bodyweight at puberty did not differ according to season of maturation, it appears that the growth rate of spring-maturing gilts was greater than that of autumn-maturing gilts. Although a lower growth rate in autumn-maturing gilts may partially explain the seasonal difference in age at puberty, the fact that a higher proportion of spring-maturing gilts reached puberty by $24 \mathrm{~kg}$ bodyweight suggests that the threshold for bodyweight at puberty was influenced by the season of maturation. While both age and weight are equally important in determining age at puberty (Brooks and Cole, 1970), age becomes the determining factor in puberty attainment when gilts are induced into puberty by exogenous factors such as increasing daylength (Mavrogenis and Robison, 1976).

Although the mechanisms responsible for the attainment of puberty in gilts are not well understood, many other factors have been identified as having an influence on the time required for this event to occur in Western breeds including: nutrition, body size, social environment, pheromonal cues, stress, confinement and genetics (see review, Christenson and Ford, 1979). As delayed puberty continues to be a problem in confinement-reared swine, the Meishan may be an ideal breed for study. However, it must be demonstrated that factors known to influence age at puberty in Western breeds also affect the Meishan breed. Within the Meishan breed, differences have been observed in age at puberty between French (Prunier and Chopineau, 1990) and UK (Haley et al., 1990; Hunter et al., 1993) populations. Given the difference in genetic base for these two populations of Meishan pig (Haley and Lee, 1993), genotypic variation is the likely factor causing this discrepancy. Interestingly, preliminary investigations into the effect of Meishan genes on age at puberty have found $\frac{1}{2}$ Meishan, $\frac{1}{2}$ Western gilts to be similar in age at puberty to purebred Meishans (Cheng, 1983; reviewed by Bazer et al., 1988a).

Our finding that the number of ova shed by gilts increased with reproductive age and approached that of first parity sows at advanced ages ( $\geq 10$ cycles) is in agreement with information attained from Western breeds showing that ovulation rate increases with both increasing number of oestrous cycles experienced and parity (Kirkwood and Aherne, 1985; Anderson, 1987). The discrepancy in the literature over ovulation rate in the Meishan breed has probably developed because of confounding factors such as age, genetics, environmental factors, number of oestrous cycles experienced and parity. Although multiparous Meishan sows clearly have a high ovulation rate (Cheng, 1983; Haley and Lee, 1990; Anderson et al., 1992; Christenson, 1992), the situation in gilts is more obscure. One report from mainland China (observing a small number of gilts) agrees with our findings, showing that young gilts (2.5 months of age) shed 10.3 ova, while gilts of 8-9 months of age experienced 19.3 ovulations (Cheng, 1983). Most reports of ovulation rate in Meishan pigs exported from China found that ovulation rates remained low (Bazer et al., 1988b; Terqui et al., 1990; Anderson et al., 1992), even when observed in gilts of 280 days of age (Christenson, 1992). In contrast, one investigation reported that gilts that had experienced 6-7 oestrous cycles had an ovulation rate of 21 ova (Ashworth et al., 1992). Paradoxically, our finding that only gilts of an advanced reproductive age ( $\geq 10$ oestrous cycles, $>300$ days of age) attain high ovulation rates is consistent with the majority of reports even though the gilts were of the same genetic foundation as those used by Ashworth et al. (1992). Haley et al. (1990) and Haley and Lee (1993) found that ovulation rate in Meishan pigs could be underestimated when determined by observation of the ovarian surface and that ovarian dissection was the most accurate method. However, in the present study, although ovulation rate was determined by laparoscopy in many of the gilts that had experienced $\geq 10$ cycles and in all primiparous sows, dissection of the ovaries was used for most $(81 \%)$ of the gilts that had experienced $<10$ oestrous cycles. Any underestimate in ovulation rate would therefore be in older gilts and sows but not in gilts of lower reproductive age. Although genetic differences may explain contradictory findings among and within Chinese, French, American and British populations of Meishan pigs, the possibility that nutritional or other environmental factors may also affect ovulation rate cannot be discounted.

The time interval between the onset of oestrus and ovulation in the present investigation was similar to that previously found for Meishan gilts ( $\approx 45 \mathrm{~h}$, Terqui et al., 1990) or sows (49 h, Wilmut et al., 1992). Reports of the oestrus onset to ovulation interval in Western breeds have demonstrated consistently that its duration is markedly shorter than that of Meishan gilts (Signoret et al., 1972; Terqui et al., 1990; Wilmut et al., 1992) and recent experiments examining oocyte maturation during the immediate preovulatory period have confirmed this in our own Large-White hybrid gilts (Faillace et al., 1992). Characterizing the chronology of events during oestrus in Meishan pigs is crucial for the study of the prolificacy of this breed, since many experiments depend on the ability to predict accurately the timing of ovulation and, subsequently, fertilization. The oestrus to ovulation interval appears to be consistent regardless of reproductive age, since subsequent investigations from our laboratory have found the time interval to ovulation to remain greater for gilts at advanced reproductive ages ( $\geq 13$ oestrous cycles, unpublished observations) and Wilmut et al. (1992) found a similar interval in Meishan sows. In addition, other results have provided evidence that this longer interval is attributable to the fact that the LH surge occurs later in Meishan gilts relative to the onset of behavioural oestrus than in Large-White hybrid gilts and that this accounts for the differences between the breeds (Hunter et al., 1993). The timing of ovulation in gilts administered hCG at first observed oestrus also supports this conclusion. Not only was the time interval from the presumed onset of oestrus to ovulation significantly shortened but, more importantly, the interval from 
the administration of hCG to ovulation was similar to that reported for Western gilts induced to ovulate with exogenous gonadotrophins (Dziuk and Baker, 1962; Hunter, 1967; Baker et al., 1969). This information suggests that the chronology of ovarian events is similar in Meishan and European gilts following the LH surge and the extended oestrus to ovulation interval is due to the earlier onset of oestrus (or a delayed LH surge) rather than to an extended interval from LH surge to ovulation.

In conclusion, these studies have confirmed the early age at onset of puberty in Meishan pigs and provided evidence that the age at puberty may be under the influence of factors known to influence puberty in Western breeds. Ovulation rate was found to increase with increasing reproductive age, but only approached that of primiparous sows when the gilts had experienced $\geq 10$ oestrous cycles. Lastly, the time interval from the onset of behavioural oestrus to ovulation was confirmed to be greater in Meishan than that reported in Western breeds and evidence was provided to support the notion that the time interval from the LH surge to ovulation is similar to that of Western breeds and supports an earlier observation that the LH surge occurs later in this breed relative to the onset of oestrus.

The authors acknowledge the AFRC for financial support. Cotswold Pig Development Company, Lincoln and IAPGR, Roslin supplied Meishan stock. C. Biggs was in receipt of a MAFF postgraduate scholarship. They thank H. M. Picton, C. Bowskill, J. Plowright and the members of the Joint Animal Breeding Unit for their help with the animal work.

\section{References}

Anderson LL (1987) Reproductive Cycles - Pigs. In Reproduction in Farm Animals, pp 335-336 Ed. ESE Hafez. Lea and Farbiger, Philadelphia

Anderson LH, Christenson LK, Christenson RK and Ford SP (1992) Investigations into the control of litter size: comparisons of Chinese (Meishan) and American pigs. In Proceedings of the International Symposium on Chinese Pig Breeds, pp 86-90 Ed. C Runsheng. Harbin, China

Ashworth CJ, Haley CS and Wilmut I (1992) Effect of regumate on ovulation rate, embryo survival and conceptus growth in Meishan and Landrace $\times$ Large White gilts Theriogenology 37 433-443

Baker RD, Mellish KS and Segal DH (1969) First polar formation and ovulation in gilts Journal of Animal Science 29 183-184

Bazer FW, Thatcher WW, Martinat-Botté F and Terqui M (1988a) Sexual maturation and morphological development of the reproductive tract in Large White and prolific Meishan pigs Joumal of Reproduction and Fertility 83 $723-728$

Bazer FW, Thatcher WW, Martinat-Botté F and Terqui M (1988b) Conceptus development in Large White and prolific Chinese Meishan pigs Journal of Reproduction and Fertility 84 37-42

Brooks PH and Cole DJA (1970) The effect of the presence of a boar in the attainment of puberty in gilts Joumal of Reproduction and Fertility $23435-440$

Cheng P-L (1983) A highly prolific pig breed of China - the Taihu pig. Pig News and Information 4 407-425
Christenson RK (1992) Ovulation rate and embryo survival in Chinese Meishan and Occidental crossbred females. In Proceedings of the International Symposium on Chinese Pig Breeds, pp 91-98 Ed. C Runsheng. Northeast Forestry University Press, Harbin

Christenson RK and Ford JJ (1979) Puberty and estrus in confinement reared gilts Journal of Animal Science 49 743-751

Dziuk PJ and Baker RD (1962) Induction and control of ovulation in swine Journal of Animal Science 21697 (Abstract)

Faillace LS, Biggs C, Craigon J and Hunter MG (1992) Preovulatory ovarian processes in Meishan and Large White gilts Journal of Reproduction and Fertility Abstract Series 10 Abstract 25

Genstat 5 Committee (1989) Genstat 5 Reference Manual, Clarendon Press, Oxford

Haley CS and Lee GS (1990) Genetic components of litter size in Meishan and Large White pigs and their crosses Proceedings of the 4th World Congress of Genetics Applied to Livestock Production Edinburgh, UK XV 458-461

Haley CS and Lee GS (1993) Genetic basis of prolificacy in Meishan pigs Journal of Reproduction and Fertility Supplement 48 247-259

Haley CS, Ashworth CJ, Lee GS, Wilmut I, Aitken RP and Ritchie W (1990) British studies on the genetics and prolificacy in the Meishan pig. In On Symposium sur le Porc Chinois, pp 83-97 Eds N Molenat and C Legault. INRA, Toulouse

Hunter MG, Biggs C, Foxcroft GR, McNeilly AS and Tilton JE (1993) Comparisons of endocrinology and behavioural events during the periovulatory period in Meishan and Large-White hybrid gilts Journal of Reproduction and Fertility $97475-480$

Hunter RHF (1967) Porcine ovulation after injection of human chorionic gonadotrophin Veterinary Record 81 21-23

Jin RB, Chui HM and Mao JD (1992) Reproductive characteristics of Taihu pigs Pig News and Information $1399 \mathrm{~N}-102 \mathrm{~N}$

Kirkwood RN and Aherne FX (1985) Energy intake, body composition and reproductive performance of the gilt Joumal of Animal Science 60 1518-1529

Mavrogenis AP and Robison OW (1976) Factors affecting puberty in swine Journal of Animal Science 42 1251-1255

Paterson AM and Pearce GP (1990) Attainment of puberty in domestic gilts reared under artificial long-day or short-day light regimens Animal Reproduction Science 23 135-144

Paterson AM, Pearce GP and D'Antuo'no (1991) Seasonal variation in attainment of puberty in isolated and boar-exposed domestic gilts Animal Reproduction Science 24 323-333

Paterson AM, Maxwell CA and Foldes A (1992) Seasonal inhibition of puberty in domestic gilts is overcome by melatonin administered orally, but not by implant Journal of Reproduction and Fertility 94 97-105

Prunier A and Chopineau M (1990) Sexual maturation of the Meishan gilt. In Symposium sur le Porc Chinois, pp 37-40 Eds N Molenat and C Legault. INRA, Toulouse

Signoret JP, du Mesnil du Buisson F and Mauleon P (1972) Effect of mating on the onset and duration of ovulation in the sow Journal of Reproduction and Fertility 31 327-330

Terqui M, Bazer FW and Martinat-Botté F (1990) Mechanisms involved in the high prolificacy of the Meishan breed. In Symposium sur le Porc Chinois, pp 17-32 Eds N Molenat and C Legault. INRA, Toulouse

Varley MA, Yang H and Rodway RG (1989) Puberty attainment in oestradioltreated gilts given allyl-trenbolone and gonadotrophins Animal Production 48 435-441

Wilmut I, Ritchie WA, Haley CS, Ashworth CJ and Aitken RP (1992) A comparison of rate and uniformity of development in Meishan and Large White pigs Journal of Reproduction and Fertility 95 45-46 